\title{
A selva invade Lima: representações amazônicas na capital
}

\author{
La selva invade Lima: representaciones amazónicas en la capital \\ The jungle invades Lima: Amazonian representations in the capital
}

\author{
Bibiana Soyaux de Almeida Rosa ${ }^{1}$
}

\begin{abstract}
Resumo
Este artigo é resultado da minha pesquisa de mestrado, "El Poder Verde de la Cumbia: a Amazônia em discos", que tem como objetivo geral compreender as relações entre a cumbia amazônica e a indústria musical peruana na formação de representações sobre a Amazônia. A Cumbia, cuja origem é colombiana, é um gênero musical muito capilarizado na América Latina, apresentando especificidades de acordo com o país, região ou locais sociais nos quais se territorializou. É, portanto, exemplo de transnacionalização da música - sendo hoje um gênero representativo da América Latina. No Peru, sua recepção foi ampla - desde a década de 1960 conquistou espaço e se misturou com outros ritmos locais desde a capital até as cidades amazônicas. Neste artigo, exploro de que modo conceitos como "música local"; "transnacionalização"; "diversidade" e "desterritorialização" podem me ajudar a pensar os processos de representação e formação identitária da região Amazônica a partir da cumbia em relação às indústrias musicais e em contextos de mundialização da cultura.
\end{abstract}

Palavras-Chave: cumbia amazônica, Fronteira Amazônica, Identidade Regional, Indústria Musical, Lima

\section{Resumen}

Este artículo es resultado de mi investigación de maestría, "El Poder Verde de la Cumbia: la Amazonia en discos", que tiene como objetivo general comprender las relaciones entre la cumbia amazónica y la industria musical peruana en la formación de representaciones sobre la Amazonia. Cumbia, cuyo origen es colombiano, es un género musical muy capilarizado en América Latina, presentando especificidades de acuerdo con el país, región o locales sociales en los que se territorializó. Es, por lo tanto, ejemplo de transnacionalización de la música, siendo hoy un género representativo de América Latina. En el Perú, su recepción fue amplia - desde la década de 1960 conquistó espacio y se mezcló con otros ritmos locales desde la capital hasta las ciudades amazónicas. En este artículo, explora de qué modo conceptos como "música local"; "transnacionalización"; "diversidad" y "desterritorialización" pueden ayudarme a pensar sobre los procesos de representación y formación identitaria de la región Amazónica a partir de la cumbia - y esta en relación a las industrias musicales en contextos de mundialización de la cultura.

Palabras claves: Cumbia Amazónica, Frontera Amazónica, Identidad Regional, Industria de la música, Lima

\begin{abstract}
This article is the result of my master's research, "El Poder Verde de la Cumbia: Amazônia em discos", whose main goal is to understand the relationship between Amazonian cumbia and the Peruvian music industry in the formation of representations about the Amazon. The Cumbia, which is originated in Colombia, is a very spread musical genre in Latin America, presenting peculiarities according to the country, region or social places in which it was territorialized. It is, therefore, an example of transnationalization of music - being nowadays a representative genre of Latin America. In Peru, its reception was wide - since the 1960's it has gained space and has mixed with other local rhythms from the capital to the Amazonian cities. In this article, I explore how concepts such as "local music"; "Transnationalization"; "Diversity" and "deterritorialization" can help me to think about the processes of representation and identity formation of the Amazon region starting from cumbia in relation to the musical industries and contexts of globalization of culture.
\end{abstract}

1 (Mestranda em Ciências Sociais; Departamento de Estudos Latino-Americanos - ELA/UnB; Brasília, Distrito Federal, Brasil; bibiana.rosa92@gmail.com).Trabalho apresentado no I Seminário Latino-Americano de Estudos em Cultura - SEMLACult, Foz do Iguaçu/PR, Brasil, 2017. 
RELACult - Revista Latino-Americana de Estudos em Cultura e Sociedade

Key-Words: Amazonian Cumbia, Amazon Border, Regional Identity, Music Industry, Lima

\section{Introdução}

A América Latina abriga uma grande variedade de expressões, gêneros e vivências musicais. Seria possível mapeá-las a partir de afinidades regionais, pela sonoridade, pelos contextos sócio-políticos aos quais pertencem e fazem referência, pela sua relação com a indústria radiofônica, pelos seus padrões de produção e consumo; enfim, é uma região cuja a diversidade e as continuidades culturais também se expressam a partir e através da música. Assim, ritmos musicais podem ser utilizados como chaves de leitura para a análise de fragmentos da realidade latino-americana. Nesse sentido, é válido ressaltar o valor cotidiano que a música tem nos países latino-americanos - essencial para rituais sociais, religiosos, vinculados à produção agrícola, sua presença se estende à sonoridade cotidiana, aos centros urbanos. As festas de carnavais, as festividades religiosas como o São João, os bailes funks nas periferias cariocas, as festividades das religiões de matrizes africanas são todas permeadas com sonoridades próprias que delineam sentidos à esses momentos. Da possibilidade de situar as expressões musicais inseridas em determinados contextos, surge a designação de "música folclórica" - aquela que pode ser vinculada a um determinado grupo social ou região. Além desta, atualizada para os contextos de urbanização e de industrialização que se intensificaram a partir das décadas de 1950 e 1960, temos a "música popular" - aquela que possui sua origem bem marcada, mas foi descolada de seus contextos originários devido a processos de migrações, industrialização e modernização dos meios de comunicação.

As duas categorizações são amplamente utilizadas para classificar os gêneros musicais dos países tidos como "Terceiro Mundo" - em oposição aos gêneros definidos em si, como o rock, o punk, o jazz, o pop entre outros - mais veiculados e geralmente associados aos países europeus e aos Estados Unidos. Tal oposição é fruto do modo de produção da música, midiatizado e difundido a partir da indústria musical. Afinal, toda expressão musical resultado de processos criativos de sujeitos históricos específicos e pertencentes a um contexto -, em maior ou menor grau revelam vínculos com o local; porém, a atuação especializada da indústria discográfica que se distanciava de ritmos locais demarcou essa diferença. Um exemplo, a partir da indústria musical, é a criação do gênero world music como categoria de mercado (Ochoa, 2003, p. 10). Dentro deste gênero se inseriam músicas locais de todo o mundo, que eram então, produzidas e veiculadas pelas grandes indústrias musicais..

Tendo em vista a diferenciação de gêneros musicais a partir da atuação da indústria musical, utilizarei o termo "música local" para me referir a determinados gêneros musicais do 
continente. A definição do termo faz referência à postulação da professora de etnomusiclogía, Ana María Ochoa:

"El término 'musicas locales' lo empleo para nombrar músicas que em algún momento histórico estuvieron claramente asociadas a un territorio y a un grupo cultural o grupos culturales específicos - aún cuando la territorilización no haya sido necesariamente contenida em sus fronteras, y en las cuales essa territorialización original sigue jugando un papel em la definición genérica." (Ochoa, 2003, p. 11)

Esta definição nos permite estabelecer bem a relação dos gêneros musicais com seus locais de origem - mas sem perder de vista os possíveis caminhos de desterritorialização e ressignificação que determinados ritmos podem apresentar. Ou seja, existem alguns ritmos que possuem um referencial de origem claramente estabelecidos, mas são amplamente difundidos e até modificados, a depender de onde se fixam. Além disso, esta definição permite situar a relação entre as músicas locais e as indústrias culturais de maneira mais orgânica - evitando maniqueísmos que são reflexos das discussões entre modernidade e tradição, globalização e homogeneização cultural. Afinal, apesar da criação das world music na década de 1980 ser, de fato, um indicativo de como as majors lidavam com as músicas locais do sul global, no decorrer do século XX essas expressões musicais apresentaram outras formas de mobilidade e transformação culturais e sociais para além da atuação das indústria musicais.

Além disso, ela própria não pode ser encarada como uma entidade monolítica e reificada que possui o monopólio do que é produzido e distribuído. Claro que existem empresas fonográficas com mais força econômica e de capacidade de veiculação - as majors; mas o final da década de 1970 inaugurou uma fase em que várias pequenas indústrias discográficas surgiam e se especializavam na produção de músicas locais - as indies (Yúdice, 2000, p. CHECAR). Foram essas pequenas indústrias fonográficas que mobilizaram e criaram importantes cenas musicais na América Latina a partir da utilização do rádio e de gravações independentes de discos. Segundo Santiago Alfaro Rotondo, um dos caminhos para compreender as dinâmicas musicais no continente é o de analisar os mercados formados ao redor de músicas populares e/ou locais, ou seja, das cenas musicais geradas pela oferta e demanda desses estilos. Segundo ele:

“... más allá de sus diferencias, todas estas escenas tienen em común estructurarse, principalmente, sobre la base de micro y pequeñas empresas de reducida división social del trabajo, una amplia red de espacios y oportunidades para la organización de coniertos, la comercialización de discos ópticos piratas y la creación y negociación de repretorios culturales ajenos al canon norte-americano. Por lo mismo, no son un ejemplo de la incorporación de géneros locales a la industria musical sino de la apropriación de esta industria por parte de productores y consumidores de géneros locales." (Rotondo, 2015, p. 131) 
Ou seja, as relações entre ritmos musicais locais com as indústrias musicais nacionais e/ou internacionais - na América Latina devem ser sempre contextualizadas. Com isso, quero dizer que, para pensarmos a música a partir de um marco temporal da modernidade - onde a existência da indústria musical e seus poderes de categorização e de hierarquização de estilos musicais são inegáveis -, é preciso pensá-la a partir de seu valor simbólico como arte (onde os processos e contextos de criação são mais relevantes) e também a partir de seu valor como mercadoria (onde os meios e contextos de produção e circulação são mais relevantes). Quero dizer, a música é uma expressão cultural e artística, portanto, pode ser considerada um discurso capaz de informar elementos referentes a territórios, locais, experiências de vida, resistências, entre outros; mas também adquire um status de mercadoria simbólica ao ser criada, distribuída e consumida massivamente a partir dos meios de comunicação e/ou pelas lógicas comerciais das indústrias culturais (Rotondo, 2015, p 133). Assim, estabeleço meu principal eixo temático: a relação das músicas locais, dentro dos contextos da América Latina, com as indústrias musicais desde meados do século XX.

América Latina, no entanto, é um grande mosaico e seria impossível estabelecer qualquer tipo de padrão para essa relação. Deve-se respeitar as particularidades e isso nos direciona a considerar várias possibilidades para compreender como as expressões musicais do continente se relacionam com a produção musical inserida na indústria músical. Nesse sentido, escolhi trabalhar a Cumbia Amazônica Peruana para ilustrar os processos desta apropriação da indústria musical por um ritmo local na construção e consolidação de um discurso identitário regional - considerados os contextos em que esses processos aconteceram.

\section{Cumbia: um ritmo transnacional}

A Cumbia é um ritmo musical cuja origem é atribuída à costa norte da Colômbia. Compõe, juntamente com o vallenato e o porro, o que ficou conhecido como "música costenha colombiana", "música caribenha colombiana" ou, simplesmente, como "música tropical". Segundo Peter Wade, esses ritmos sofreram intenso processo de midiatização e modernização a partir da década de 1940, período em que a indústria radiofônica colombiana começou a se estruturar (2000, p. 144). Nesse processo, os ritmos, até então marginalizados devido às suas origens afrodescendentes, começaram a se integrar aos discursos nacionais sofrendo, claro, processos de embranquecimento. Em "Music, Race and Nation", Peter Wade (2000) discute as construções da negritude a partir dessa relação entre a música costenha - 
majoritariamente negra - e os discursos nacionais que a elevaram como elemento de identidade nacional. Segundo ele, compreender como os processos de apropriação deste tipo de música local pela indústria, e vice-versa, pode nos ajudar a compreender as relações raciais e as construções identitárias acionadas por fatores raciais e regionais no país. Em sua análise, as relações da música com a indústria musical e o consumo de música são fatores centrais de reflexão. Por mais que tais ritmos locais tenham sido absorvidos ao longo do tempo pela indústria musical de nível nacional e internacional - sob um processo de embranquecimento e modernização -, eles ainda conservaram elementos originários de negritude, referentes à região norte da costa colombiana. Sobre esse complexo processo de desterritorialização de músicas locias, Wade argumenta:

\footnotetext{
"There is no simple opposition between the local and the national (or between these and the global), or between the traditional and the modern. Instead, the music "in the barrio" was actually created in complex processes of interchange, class mediation, and appropriation that worked in ambiguous spaces between country and city, between social classes and, not infrequently, between the national and de international. [...] and its necessary to appreciate that the music that is modernizedand nationalized has to be defined against something else that remains putatively tradditional and nonnational (i.e., local): if everything is appropriated and made national, than the danger or erasing hierarchies of class and culture rears its head." (Wade, 2000, p. 8)
}

As relações que se estabelecem, bem como os discursos identitários decorrentes da relação entre música local com o nacional, e destes com o internacional, não são simples. Assim como também são complexos e diversos os meandros de tais processos. Dessa forma, como já foi dito anteriormente, seria uma interpretação simplista defender que tais ritmos locais se submetem às lógicas do comércio e viram apenas mercadorias - bem como é simplista dizer que tais ritmos se submeteram ao discurso hegemônico das elites colombianas a respeito do que é ser colombiano. Como Peter Wade defende, há uma negritude permitida construída a partir deste processo de nacionalização da música costenha, mas há também outras negritudes que resistem e negociam a partir dessa relação:

"A nationalist project can articulate a variety of elements that have different locations, in terms of, say, putative class or racial origin, and give them some coherence as part of a hegemony, without fixing their meaning completely. Thus, music from the Caribbean coastal region of Colombia could be resignifed as a national music by relocating it in relation to other elements rather than by simply obliterating irs former meaning." (Wade, 2000, p. 10)

As músicas locais, portanto, carregam consigo informações acerca das localidades às quais pertencem, e podem ser realocadas como elementos identitários a partir de seu amplo consumo. O caso das músicas tropicais colombianas - a cumbia, o vallenato e o porro - é interessante porque, além da ampla distribuição e consumo à nível nacional - desencadeando a discussão acerca da identidade nacional levantada por Wade -, elas sofreram intenso 
processo de internacionalização. Por fim, tais ritmos consolidaram-se como músicas típicas caribenhas e costenhas, comunicando discursos identitários sobre a região para os países latino-americanos e, inclusive, sobre a América Latina para o mundo.

A internacionalização dos ritmos tropicais colombianos se deu na década de 1950 e na década de 1960, período de ouro da música costenha. A incipiente indústria musical nacional que se originou na década de 1940 ganhava mais força: durante esses anos, algumas empresas de gravação e de rádio abriram e se instalaram em cidades importantes do país. Além das antigas gravadoras de Cartagena e Barranquilla, neste período novas empresas especializadas nos ritmos costenhos se instalaram em Medelín e Bogotá (2000, p. 144). A profusão da indústria musical nas cidades centrais da Colômbia, principalmente Medelín, centro comercial e industrial do país, tensionaram as relações identitárias no negócio da música. Houve, segundo Peter Wade, um deslocamento da produção de música costenha da sua região de origem para a região central do país. A consolidação destes ritmos, no mercado internacional, sob a nomenclatura de "música tropical" revela o processo.

Nesse contexto houve o boom da Cumbia e, a partir da década de 1950, o gênero musical se capilarizou pelo continente. Hoje, temos expressões do gênero - denominado cumbia - do México até o Uruguai, cada um com suas variações e peculiaridades. Para Wade, a internacionalização da Cumbia deveu-se, primeiramente, devido à consolidação da indústria fonográfica e discográfica da Colômbia. Outra questão que ele aponta como pergunta propícia para investigação é a cumbia ter sido o gênero que se popularizou no restante da América Latina - em vez do porro ou do vallenato (Wade, 2000, p. 175). Ele levanta algumas possibilidades. A primeira é que a cumbia se popularizou no país no final da década de 1950, enquanto o porro conheceu seu auge na década de 1940 e, nos anos 1950, já estava sendo deixado de lado pela indústria radiofônica. Outro ponto levantado pelo autor é que a cumbia, apesar de sua popularização, não alcançou naquele momento o mercado internacional mainstream - tomado pela salsa e pelo merengue. O que nos permite afirmar que a cumbia tinha um perfil mais regional, ou seja, fazia mais sucesso e era mais consumida em regiões do campo ou de periferias (Wade, 20000, pp. 175 - 176). Foi justamente nessas regiões que o gênero se fixou, em países como o México, o Peru e Venezuela.

De fato, para compreender os motivos e os padrões da internacionalização da cumbia, caberia outros estudos - inclusive estudos comparativos entre os países. Mas é inegável a amplitude que o gênero cumbia tem no continente latino-americano. E mais, se em meados e finais do século XX, a cumbia não era o gênero latino-americano mais representativo no 
mercado mundial, no decorrer do século XXI a coisa começou a mudar um pouco de figura. A capilaridade que a cumbia alcançou e hoje apresenta é tão grande que a faz ser considerada um objeto transnacional passível de pesquisa pelas Ciências Sociais, fértil para lançar luzes sobre as questões de identidades culturais na globalização. Segundo Pablo Vila e Héctor L'Hoeste (2013, p. 13), a cumbia pode ser considerada o gênero musical mais difundido da América Latina. Ao pesquisá-la, é possível notar mecanismos nos quais diferentes tipos de identidade (nacional, racial, regional, de gênero, etc) são ativadas, negociadas e incorporadas, de modo que sua expansão pelo continente pode revelar vários tipos de processos identitários impulsionados pela cumbia ao se territorializar em diferentes países.

No Peru, a cumbia colombiana inicialmente teve maior impacto entre a juventude de classe média, mas rapidamente foi substituída pela salsa ou pelo rock britânico. No entanto, a partir da década de 1970, a cumbia ganhou espaço entre as populações urbanas de classe baixa, principalmente entre os migrantes que tentavam se estabelecer em Lima (Wade, 2000, p. 174). Segundo Raúl R. Romero (2007, pp. 21-22), o advento da cumbia na música popular peruana é característica de dois processos: sua fácil aceitação em zonas rurais do país e sua hibridação com o huayno, musica típica das populações Andinas do Peru. No mais, a trajetória da cumbia no Peru corresponde com a análise de Wade quanto ao seu caráter regional. Portanto, além de se desterritorializar e se fixar em países fora da Colômbia, a cumbia também desencadeou processos de regionalização dentro desses outros países - como é o caso peruana. Lá, temos expressões da cumbia a partir da regioão costenha, serrana e amazônica, comunicando diferentes tipos de representações regionais.

Para ele, tanto a popularização do huayno quanto da cumbia no Peru se deve aos movimentos migratórios internos ao país. Em momento anterior, o huayno rural se converteu em êxito comercial urbano devido ao grande fluxo migratório das populações andinas a Lima, gerando um mercado interno urbano que consumia o huayno como forma de conexão com a experiência andina deixada para trás. A época de ouro do huayno comecial foi entre 1950 e 1980, período em que passou de um contexto local para um contexto nacional e que inaugurou no Peru a prática do uso de amplificadores, representações cênicas e outros recursos modernos para transcender seu regionalismo (Romero, 2007, p. 16). O huayno foi a música preferida dos imigrantes de Lima desta época e representava um mercado musical que também demandava outros gêneros musicais, representando a experiência multicultural vivenciada por essas pessoas em uma grande cidade. Esse foi o cenário favorável que absorveu a cumbia colombiana a partir da década de 1970 e que, a partir da década 1980, ao 
misturá-la com huayno, gerou o que foi considerado a cumbia peruana por excelência, a chicha.

Mas a influência da cumbia colombiana no Peru não se encerrou em Lima e não se limitou a representar a identidade do migrante andino nas regiões urbanas da capital. Apesar de não ter obtido tanta popularidade e circulação durante os anos setenta e oitenta, a cumbia amazônica foi um elemento importante para a formação da identidade regional na Amazônia (Metz. 2013: 171). Na região, o ritmo marcado da cumbia colombiana e o compasso acentuado pelos tambores de origem africana foram muito bem recebidos pelos mais variados ritmos populares da região - inclusive a toada brasileira. Já nos anos 1970 havia grupos musicais das regiões amazônicas que se identificavam como grupos de cumbia amazônica e faziam questão de evidenciar a identificação de suas músicas com a selva, como é o caso do grupo Los Wemblers, de Iquitos e Juaneco y Su Combo, de Pucallpa.

Outros grupos de cumbia selvática também surgiram nessa época, um exemplo emblemático é Los Mirlos e Garotos de Iquitos, que junto à Los Wemblers e Juaneco, formaram o que chamavam de música tropical de la selva. Foi do grupo Los Mirlos que surgiu a expressão "poder verde", que se referia à floresta e a força da sua sonoridade, representada pelos ritmos da região, entre eles a cumbia, que despontava a partir da década de 1970. Assim, diferente da cumbia/chicha que tomou lugar em Lima e representava a vida do migrante andino - com músicas que poderiam causar sentimento de nostalgia e letras carregadas de críticas sociais e de ilustração da vida em uma grande cidade -, a cumbia amazônica é predominantemente instrumental, com bastante elementos sonoros e letras simples e repetitivas, que geralmente fazem referência direta a elementos da região da selva amazônica, suas características gerais e alguns elementos culturais específicos como tipo de frutas e comidas da região, festas ou costumes específicos de algum grupo indígena, etc.

\section{Construção de discursos identitários a partir da música}

Levando em conta o caráter transnacional da cumbia, os processos de absorção desta no Peru e a decorrente consolidação de outros ritmos regionais atribuídos ao gênero no país, pretendo analisar as relações entre a cumbia amazônica e a indústria fonográfica peruana, com enfoque no discurso identitário regional proveniente desta interação. Para tal, considero importante delimitar os recortes com os quais trabalho, que tem a ver com escolhas de pesquisa, mas também com limitações de tempo e de acesso a fontes.

O meu principal objeto de estudo é a Industria Fonográfica Peruana (INFOPESA), empresa de gravação e distribuição de vinis inaugurada em 1971 por um experiente produtor 
musical, Alberto Maraví. Sua atuação era especializada. Maraví pesquisava e contratava grupos de ritmos locais e populares no país para gravarem pelo selo da INFOPESA. Ao lado da gravadora, selecionou, produziu e gravou duas bandas de cumbia amazônica que foram e são importantes representates do gênero, Los Mirlos e Juaneco y Su Combo. Os meus dados de análise são entrevistas que realizei com Maraví e Juan Ricardo Maraví, seu filho, hoje gerente da INFOPESA, e com Don Jorge Rodrígues, vocalista e líder de Los Mirlos; reportagens que tratam do assunto; e as capas e músicas de seus discos.

Minha análise se restringe aos contextos de Lima na época de 1970, onde a INFOPESA funcionava e seu principal raio de alcance. Importante ressaltar também que não trabalho com dados que possibilitem, estatisticamente, mensurar ou mesmo estimar o consumo da música desses dois grupos. Assim, minha chave de leitura para este trabalho é compreender, a partir dos contextos culturais latino-americanos, de intercâmbio musical e de surgimento de indústrias musicais endógenas, como a cumbia amazônica peruana pode ser considerada produto simbólico importante na construção de discursos identitários para a região amazônica. Ou seja, trata-se de uma biografia social da gravadora e dessas bandas, sob as luzes do debate teórico a respeito de música popular, identidades regionais em contextos de globalização e indústria cultural latino-americana.

Nesse sentido, pretendo delinear algumas dessas discussões teóricas que percebo como essenciais para a análise. Em primeiro lugar, é relevante ressaltar que meu objetivo não é o de afirmar que tal "discurso identitário" tenha sido fruto de um projeto de afirmação cultural ou identitária para a região; considero que as relações entre os artistas, produtores e a indústria são orgânicas, mas ao mesmo tempo obedecem lógicas de mercado. Situo, portanto, minha análise nesse sentido: como tais relações se deram e o que seus contextos permitem nos dizer sobre a cumbia amazônica como um produto simbólico rico em referências regionais da Amazônia. A segunda é compreender a "música popular/local" como símbolo da diferença/diversidade dentro da indústria musical - elemento que sinaliza o contexto de globalização ao qual está inserida ${ }^{2}$. .

\footnotetext{
2Utilizo o termo "situação de globalização" baseado na construção teórica de Renato Ortiz a respeito das relações entre cultura e globalização: "Do ponto de vista conceitual, ao operar com a ideia de situação, consigo evitar um tipo de dicotomia comum no debate atual: refiro-me aos pares de oposição moderno/pós-moderno, tradição/modernidade, velho/novo, passado/presente. [...] A situação de globalização caracteriza-se pela emergência do novo e pela redefinição do velho, ambos encontram-se inseridos no mesmo contexto, no qual diversas temporalidades se entrecruzam." (Ortiz, 2015, p. 25)
} 
Peter Wade (Wade, 2000) analisa o papel da música tropical costenha nas relações étnico-raciais dentro das concepções de nacionalidade da Colômbia. A indústria fonográfia, a televisão e, a partir da década de 1940, a indústria musical nacional que começava a se desenvolver, foram importantes nesse processo. Afinal, a partir desses meios de comunicação, esses gêneros musicais passaram a ser amplamente comercializados - não só dentro do país, mas internacionalmente - ocasionando o que o autor chamou de tropicalizaçao da Colômbia (Wade, 2000, p. 29). Essa abordagem levanta questões teóricas que geralmente se polarizam entre uma interpretação mais negativa em relação aos processos de modernização das músicas locais, que é a simplificação e perda de suas autenticidades; e outra interpretação que julga positivo a popularização desses ritmos, uma vez que podem desafiar narrativas oficiais e hegemônicas de uma nação. Acredito que a resposta está em algum ponto entre esses dois extremos e, principalmente, deve ser observado cada caso específico.

No que diz respeito à música costenha colombiana, Wade chama atenção que esta apropriação dos estilos musicais costenhos pela indústria musical e a decorrente transformação destes em música popular altamente comercializada se deu pelas mãos dos musicistas provincianos ou, quando muito, por uma classe média rural ou por trabalhadores urbanos, interessados em música. Grande parte da veiculação dessas músicas na rádio ou em indústrias fonográficas foram fruto de inciativas de empresários de médio porte, com vínculos com os estilos musicais locais, mas também com interesse em fazer dinheiro. Ou seja, era um negócio cujo sucesso tinha muito a ver com a música que era consumida - e os ritmos locais eram grandes potenciais nesse sentido. Por outro lado, considero um risco romantizar o crescimento de ritmos populares/locais pela indústria musical de forma ingênua. No caso colombiano, por exemplo, Wade chama atenção: por mais que a participação dos musicistas locais, da Costa caribenha, e da iniciativa de empresas de médio porte no processo, a música costenha que foi incorporada como participante da identidade nacional não era tão negra assim - ou seja, durante esse processo também houve o embranquecimento da música para que ela se tornasse mais palatável aos públicos de classe média e alta das capitais colombianas (Wade, 2000, p. 11).

A discussão sobre música popular na América Latina deve passar pelo crivo das indústrias musicais e da comercialização. Os processos de transformação e apropriação musical nos países latino-americanos foram comuns e recorrentes desde meados do século XIX e intensificados durante o século XX. Fenômenos como a inserção da rádio e da televisão, as migrações e o crescimento das áreas urbanas, entre outros, mudaram a forma de se ouvir e produzir música no continente (Wade, 2000, p. 47). O fato é que, quando falo de 
cumbia, estou falando de um gênero recente, do século XIX - cujo surgimento é devido a hibridações culturais típicas das relações modernas de colonização, industrialização e comercialização da música. No entanto, ainda é um gênero que nos remete a um passado mais longínquo - onde as tradições africanas e indígenas são pujantes. Isso acontece porque, de fato, há vários elementos que denunciam continuidades com tradições musicais e de dança de populações indígenas e africanas da região costenha colombiana - Peter Wade inclusive sustenta que, dentre os gêneros tropicais, a Cumbia é a que menos apresenta elementos do europeu, sendo um gênero que faz alusão a uma miscigenação apenas entre indígenas e afrodescendentes (Wade, 2000, p. 61). Mas, é um gênero que surgiu em um momento em que a Colômbia estava imersa na influência musical cubana e venezuelana - e se alastrou pelo continente em um momento em que o intercâmbio musical entre os países era alto devido às rádios. Portanto, considero que a cumbia é um gênero musical rico para compreender os processos de identificação e formação de gêneros musicais típicos de determinada região afinal, considero que a música deve ser interpretada como elemento constitutivo de identidades, não apenas reflexivo destas.

A segunda discussão teórica que considero importante é a respeito das relações entre diversidade - uma vez que as músicas populares são consideradas específicas dentro da indústria musical - e globalização. Segundo Renato Ortiz, a diversidade pode ser considerada hoje um emblema da modernidade-mundo - e entender como a pensamos e a utilizamos pode dizer muito sobre a nossa contemporaneidade (2015, p. 11). Sendo assim, o importante não é pensar no quanto o mundo pode se tornar homogêneo com a marcha da globalização e das trocas culturais dela decorrentes, nem pensar em que termos o mundo era diverso no passado. As sociedades já se reconheciam como diferentes nos "tempos dos gregos" e estas diferenças já eram consideradas dentro das análises e produções textuais dos primeiros cronistas e antropólogos. Nesses contextos, a diversidade (aqui, sinônimo de diferença) é relativa a situações históricas específicas, não carrega valor em si, não se apresenta como essência. Nesse sentido, o que Renato Ortiz argumenta é que a diversidade adquiriu, em contextos de globalização, valor em si. Se na tradição iluminista - da qual as sociedades ocidentais são herdeiras - o universal era uma categoria inerente ao gênero humano e, portanto, ideal - hoje a diversidade passa a ser elevada à valor universal. Diversidade e universal, então, passam a se relacionar de outra maneira, não excludente:

"Universal e particular são um par antitético. O primeiro termo nos remete à ideia de expansão; o segundo, à de contenção, limites. A diferença associa-se ao particular, ao específico, e, em princípio, contrasta com a totalidade e a abrangência do universal. Não se trata de considerar tal polarização uma incompatibilidade entre substâncias distintas, mas 
de notar que elas configuram qualidades que se encontram tensionadas por uma relação hierárquica. [...]. Entretanto, na situação de globalização, muitas vezes esse par antagônico se entrelaça, mesclando alguns valores antes fixados apenas a um de seus polos. Subverte-se, dessa forma, a relação existente entre eles. A afirmação de que a 'diversidade dos povos deve ser preservada', utilizada em diversos documentos que orientam as políticas culturais, nada tem de natural. Pelo contrário, deveríamos nos surpreender diante de seu enunciado, que carrega consigo uma carga de sentido inteiramente nova. Dizer que as culturas são um 'patrimônio da humanidade' significa considerar a diversidade de um traço partilhado por todos, que deveríamos respeitar e cultivar." (Ortiz, 2015, pp. 33-34)

Esta construção teórica de Ortiz a respeito da diversidade como emblema da contemporaneidade e reogarnizadora dos "novos" e "velhos" espaços, me auxiliam a pensar em como a "música local", representante da diversidade, redimensiona as noções do local na formação de identidades. Dessa forma, outras relações com o total (a nação, o continente ou o mundo globalizado) são estabelecidas. Afinal, "qualquer identidade é uma construção simbólica que se faz em relação a um referente, e já certamente uma multiplicidade deles: étnicos, nacionais, de gênero etc" (Ortiz, 2015, p. 30); portanto a música participa de tal construção simbólica ao informar, a partir das letras e estética, discursos sobre o local ao qual faz referência - e o interessante nesse caso é que as cumbias peruanas tem como principal referente a região ${ }^{3}$.

A antropóloga Paula Montero sugere que a identidade, no contexto contemporâneo é um conceito antropológico capaz de atribuir poder explicativo para as diferenças (1997, pp. 50). Em ensaio intitulado "Globalização, Identidade e Diferença", Montero pretende estabelecer uma reflexão sobre o lugar que a diferença assume em um mundo contemporâneo e globalizado, analisando como a percepção da diferença pela perspectiva ocidental sofreu mudanças - possibilitando o surgimento da antropologia e, hoje, novas maneiras de se pensar a diferença. A primeira parte de sua análise se debruça em como a Europa catalogava a diferença para classificar de forma hierárquica culturas às suas - dos bárbaros aos selvagens , o que colocava o "Outro" em um lugar de subjugação. Na segunda parte, a autora sugere que o século XIX - a partir do historicismo evolucionista e da antropologia emergente - foi um momento em que as percepções sobre a diferença foram deslocadas do âmbito da natureza

\footnotetext{
3Pablo Vila e Héctor Fernandez L'Hoeste, em "Cumbia!: Scenes of a Migrant Latin American Music Genre", de 2013, defendem que a Cumbia é o gênero mais capilarizado da América Latina e opera diferentes tipos de processos identitários. No caso da Argentina, por exemplo, a Cumbia Villera se refere aos bairros periféricos (as Villas Misera) e, lá, a Cumbia opera identidades relacionadas à questões de classe social e, também, ao lugar das mulheres nesse contexto. Na Colômbia, como já vimos com Peter Wade, a música tropical tensionou questões de raça - os locais da negritude no imaginário nacional. No Peru, a cumbia se dividiu em três tipos principais: a amazônica, a costenha e a andina.
} 
para o âmbito dos costumes, da cultura. Sendo assim, segundo a autora, a alteridade percebida como diferença cultural entre sociedades é uma atitude datada a partir da modernidade:

"Nesse processo, o pensamento transforma o selvagem em primitivo - momento primeiro de nossa própria sociedade e chave para a decifração do enigma de nossas origens. Completase o movimento que desloca a alteridade da natureza para a cultura, tornando-a não mais imutável e dada, mas sujeita ao movimento da história. É apenas nesse momento que a alteridade pode ser concebida em termos de diferenças de costumes e ganhar o estatuto de objeto epistemológico. É apenas nesse momento que se pode postular a diferença de cultura como objeto de conhecimento empírico." (Montero, 1997, p. 55)

Outra consequência dessa operação intelectual é a do surgimento da antropologia como base para a colonização de caráter científico do século XIX. Assim, a autora inicia a terceira parte de sua análise para refletir como a antropologia, agora já consolidada como disciplina, abordava as questões das diferenças culturais. Nesse momento a autora analisou alguns dos aportes da teoria evolucionista e funcionalista para compreender como a disciplina antropológica equacionava as questões da "variedade". Segundo ela, mesmo com suas diferenças, ambas teorias retomaram a ideia do "homem primitivo" ao pensar a alteridade e, com isso, cada uma a seu modo, consolidaram o eurocentrismo ao interpretá-la ou partir de diferenças racias ou essencializando tradições (Montero, 1997, p. 59)

A quarta e última parte da análise trata da suposição da autora de que os processos de globalização deslocaram novamente as questões das diferenças culturais. Para ela, a distância geográfica ainda por muitos insuperáveis, e a condição de isolamento que as culturas exóticas guardavam umas em relação as outras, sustentaram o modelo de interpretação das diferenças fornecidos pela antropologia até então. No entanto, os processos de globalização - marcado pelo desenvolvimento tecnológico de transportes e informação, causando encurtamento dessas distâncias - geraram discussões a respeito da homogeneização do mundo, aculturação de povos tradicionais e, nesse momento, a antropologia se pergunta se estava de fato perdendo seu objeto. Tal pergunta, após algumas décadas de crescimento e convivências com tais processos, transformou-se em outra: como, em que bases e por que algumas expressões culturais persistem apesar da globalização? ${ }^{4}$ Segundo ela, foi essa mudança de questionamento que desafiou os modelos explicativos novescentistas da antropologia: a essencialização do funcionalismo não explicava as mudanças e transformações nas sociedades

\footnotetext{
${ }^{4}$ Vale ressaltar que autora escreveu este ensaio no ano de 1997. Por isso muitos dos debates que a autora apresenta, hoje, podem parecer atrasados. Mas, de qualquer forma, considero que suas reflexões sobre a identidade como conceito que surge na contemporaneidade para dar sentido explicativo às diferenças culturais é extremamente interessante para refletir sobre meu tema de pesquisa.
} 
ditas tradicionais, muito menos a essencialização histórica que o evolucionismo propunha dava conta de explicar a coexistência desses grupos com o mundo moderno globalizado. Também, pessoas pertencentes a essas sociedades "primitivas" e/ou "tradicionas" permaneceram, resistiram e foram se mobilizando política e socialmente cada vez mais, de forma a utilizar os conhecimentos antropológicos e da linguagem política para reivindicar direitos baseados na diferença cultural, étnica:

Ao mesmo tempo, à medida que vai se desvanecendo a ilusão antropológica das sociedades isoladas, emerge o problema - ao mesmo tempo teórico e político — da identidade étnica. Se a noção de identidade pode ser compreendida como uma forma de representação coletiva que designa pertencimentos, a identidade étnica será uma maneira de nomear e ordenar as diferenças que toma como elementos de representação traços particulares de uma cultura.

Uma vertente importante do debate em torno das identidades coletivas se inaugura no contexto da construção dos Estados nacionais - nas Américas no século XIX e na África na segunda metade do XX. Uma das características desse tipo de identidade coletiva é o fato de ele se forjar a partir de elementos culturais facilmente universalizáveis, fazendo coincidir

simbolicamente uma cultura, um território e uma forma de organização política. As identidades nacionais se forjam, portanto, no sentido da domesticação das diferenças e das particularidades. (Montero, 1997, p. 60)

A noção de identidade, portanto, é ressignificada na contemporaneidade com um viés político cultural - dando à diferença um poder explicativo e de negociação frente ao todo - ao global, ao padrão. O que mais me interessa nessa reflexão da autora é que o caráter relacional das formações identitárias é tomado como princípio para os mesmos. Ou seja, é preciso compreender os processos de identidades de determinado grupo ou sociedade a partir das auto-designações e partir dos processos que dão substrato para tal: e essas operações se dão nas fronteiras. Nesse momento, Montero recorre à Frederich Bath e seu clássico "Grupos étnicos e suas fronteiras", para reforçar a ideia de que é um problema pensar as identidades apenas a partir das diferenças culturais marcadas por línguas, religiões, costumes etc, pois isso levaria à essencialização dessas diferenças e, portanto, das identidades. Conclui:

Ora, as identidades não resultam espontaneamente do pertencimento empírico a uma cultura. Seriam, ao contrário, consequência de um processo simbólico de autodesignação de traços culturais - mesmo daqueles que podem ser fisicamente aferidos como ausentes que retira sua inspiração de um repertório cultural disponível (próprio ou alheio). Desse modo, a continuidade de uma etnia dependerá da capacidade de um determinado grupo de manter simbolicamente suas fronteiras de diferenciação, ou, dito de outra maneira, de sua capacidade de manter uma codificação permanentemente renovada das diferenças culturais que o distinguem dos grupos vizinhos.[...]

No contexto da cena contemporânea, a identidade cultural e a diversidade se carregam pois de significados simbólicos capazes de mobilizar poderosamente e criar, à sua imagem, os grupos que elas designam.

As identidades culturais, portanto, são produto de construções simbólicas - de caráter relacional - que dependem de um repertório cultural disponível. Considero, nesse sentido, que 
a música - ou a prática musical - de uma região pode ser considerada elemento desse repertório cultural e, portanto, substrato para a construção de elementos de identificação para aquelas e aqueles que mantém qualquer tipo de vínculo com aquela região.

Trouxe a disussão proposta por Paula Montero à tona por considera-la relevante para situar meu objeto de pesquisa. Como já dito, a cumbia é um gênero recente, datado da década de 1950. Sua consolidação e internacionalização a partir da Colômbia deveu-se à atuação da indústria musical - na figura das rádios e das empresas de discos - recém-consolidada no país. A sua recepção em outros países do continente também passa por transmissão de rádios e sua territorialização nesses espaços se dá a partir de fusão com outros gêneros e, no caso peruano, com a inserção da guitarra elétrica em sua execução. Ou seja, é um símbolo das trocas promovidas pelas novas tecnologias da rádio e da indústria da música, mas também é sinal da afinidade entre essas regiões.

A proposta teórica de Montero é condizente com o contexto do surgimento da cumbia, bem como com a abordagem que pretendo usar em minha análise. Ela defende que nos deparamos hoje com um processo cada vez mais intenso de circulação de produtos simbólicos, por isso o foco não pode mais se dar em conformações das estruturas lógicas dentro de cada ecologia cultural. Se a cumbia amazônica apresenta um poder de enunciar uma identidade regional, então meu interesse é pensar que tipo de espaço cultural existia para propiciar esse fenômeno. É nesse sentido que defendo que a análise deste gênero musical precisa passar pela indústria musical à época - com o cuidado de não atribuir protagonismos em demasia ou reificá-la de qualquer forma. Termino esta sessão, portanto, retomando meus recortes: situo minha análise em Lima a partir da década de 1970, a partir da análise da INFOPESA e de sua atuação como produtora e veiculadora da cumbia amazônica. A minha proposta é que tanto Lima, quanto as cidades amazônicas fornecedoras de grupos de cumbia, eram palco de processos de trocas culturais intensas, caracterizando um espaço intercultural propício para que o fenômeno da cumbia peruana tomasse o país.

\section{Espaços Interculturais na Globalização}

Recorro novamente a Renato Ortiz para pensar a mundialização da cultura como um processo que se realiza a partir da formação de espaços interculturais gerados pelos processos de globalização e de formação de uma modernidade-mundo. Segundo Renato Ortiz (1994), a globalização deve ser entendida a partir do seu caráter cultural: as dinâmicas culturais são afetadas por uma nova configuração do mundo, onde as culturas locais interagem e fazem 
parte dos circuitos transnacionais. Os processos de globalização geram mudanças espaciais e essas mudanças espaciais tensionam as culturas populares/locais. Por isso o termo mundialização da cultura corresponde a uma análise dos conjuntos de valores e visões de mundo que se relacionam e formam um texto cultural amplo. No entanto, não se pode esquecer que tal processo de mundialização da cultura tem história e se realiza de diferentes formas, ritmos e jeitos - e o processo dessa mundialização se realiza não somente na desterritorialização de elementos culturais locais, mas também na sua reterritorialização (Ortiz, 2005, p. 64)

Em "Um outro território - ensaio sobre a mundialização", Ortiz (2005) lança mão da metáfora da viagem como retirada do mundo para iniciar suas reflexões sobre a mundialização da cultura nos contextos da modernidade-mundo. $\mathrm{O}$ ato de viajar representava o conhecer o outro, era um ato de busca pela alteridade. Em relação às culturas populares, agiria como substância simbólica que articularia essa busca pela alteridade à nação. Ortiz prossegue seu argumento defendendo que tal relação se perde no mundo contemporâneo tanto devido às mudanças que o ato de viajar sofreu, quanto pela relação das culturas populares em relação à nação. No entanto, ele defende que a mundialização da cultura e do espaço são marcados por transversalidades, possibilitando que as percepções e noções de cultura-mundo; cultura-nacional e cultura local sejam analisadas de formas a não hierarquizálas ou reificá-las, como poderia ser caso a perspectiva da globalização adotada fosse puramente econômica ou ideológica:

"A modernidade-mundo somente se realiza quando ela se 'localiza', conferindo sentido ao comportamento e à conduta dos indivíduos. Nesse sentido, a oposição entre mundial/nacional/local, um dado do senso comum, é um falso problema.

Uma primeira implicação da ideia de transversalidade resulta na constituição de territorialidades desvinculadas do meio físico. Se tomarmos o vetor da mundialização, na sua articulação interna, é possível discernir um conjunto de rearranjos espaciais que já não se circunscrevem mais aos limites da nação ou das localidades." (Ortiz, 2005, pp. 63-64)

Pego emprestada a ideia de viagem para aplicá-la à cumbia. Desde a Colômbia, tal sonoridade viajou por meio das frequências de rádio; discos; trocas de ideias e de apresentações e viajou pelo continente se desterritorializando e territorializando nos mais diversos espaços, que agora pertencem a um espaço - permito-me agora um pequeno neologismo - cumbiesco. Penso, portanto, que a cumbia é um elemento cultural muito ilustrativo para demarcar esses processos de desterritorialização/reterritorialização de referências culturais. E Lima, devido ao contexto de migrações internas e de urbanização e 
industrialização - inclusive a da música - aponta como um lugar interessante para pensar como esses processos se dão.

\subsection{Lima e a consolidação da Cumbia Peruana}

A urbanização tensiona as relações das práticas de música popular. Esse fenômeno é ainda mais intensificado com a atuação das indústrias culturais e a mercantilização de produtos simbólicos referentes a essas tradições. As cidades, portanto, são mosaicos de locais que carregam em si diferentes práticas sociais e culturais - e, mesmo se relacionando entre si nesse mesmo espaço urbano, guardam particularidades e comunicam diferentes textos culturais. Nessa perspectiva, Julio Mendívil propõe que a análise sobre as vivências e práticas musicais em Lima no início do século XX seja realizada a partir da identificação de cenas musicais dentro da cartografia social da cidade. Essas cenas musicais servem como indicativos para estabelecer vínculos entre contexto social e práticas musicais, ou seja, são definidas como espaços culturais que constroem subjetividades coletivas que podem ser capturadas pela música (Mendívil, 2015, p. 18)

Trabalhar com a ideia de "cena musical" é interessante pois sugere uma dinamicidade para os fenômenos musicais e ajuda a não essencializar seus atores; ou seja, as cenas musicais são espaços delimitados a lugares e duração específicos, onde produtores, músicos, fãs e consumidores de música experimentam e constroem gostos e práticas musicais comuns, diferenciando-se do resto (Mendívil, 2015, p. 27). A cidade de Lima, fundada em 1535 como ponto estratégico para a comunicação com a península ibérica, teve suas práticas musicais marcadas nessa dinâmica colonial que já estava bem estabelecida no território peruano - Lima era um contraponto à cidade de Cusco, capital imperial até então.

Música era ensinada pelo clero católico e, assim, as músicas tradicionais/populares foram limitadas a práticas em espaço privado. Apenas em festas pátrias e feriados religiosos que as músicas tradicionais eram toleradas no espaço público. Segundo o autor, nesse contexto as músicas afrodescendentes eram mais presentas do que as expressões indígenas na cidade de Lima - que eram consideradas elemento cultural externo à formação urbana de Lima (Mendívil, 2015, pp. 26 -77). As práticas musicais em Lima permaneceram as mesmas e pouco mudou com a independência e a formação da república. Ainda nos primeiros anos do século XX, Lima era um conglomerado de bairros em torno dos edifícios públicos e prédios do governo. Nesse sentido, as práticas musicais eram passadas adiante pela tradição oral, por meio de festivais, serenatas e festividades públicas. 
A prática musical sofreu modificações mais contundentes a partir da inserção de meios de comunicação em massa - a rádio, principalmente, e com o advento do filme sonoro. Uma das mudanças foi que Lima agora recebia influências de ritmos externos - ou seja, nem locais nem nacionais - que modificavam o estilo dos compositores e artistas, bem como o consumo das pessoas. A modernização da malha urbana também colaborou que as pessoas pudessem transitar mais pela cidade - gerando intercâmbios musicais e de influências. Considerando que a música criolla - afrodescendente - era a mais tocada nos bairros limenses no começo do século XX, ela se expandiu pela cidade, fazendo oposição e também influenciando a música clássica e de orquestra pertencente às elites e às camadas mais cultas da sociedade. Segundo Mendívil:

“Con ello [as modificações que Lima sofreu no início do século XX] se inició un proceso de homogeneización de lo criollo que, entre outras cosas, terminó de incorporar completamente lo afroperuano como componente sonora de la ciudade limeña. A esta Lima no pertenecía, por cierto,la música indígena. [...] Lima era criolla. Pero si hasta entonces la música criolla había aparecido unida a los bairros populares de la capital, com su profesionalización em los años cincuenta pasó a ser parte del imaginario de las clases medias y atas, ganando así presencia em los balnearios y em los bairros exclusivos." (Mendívil, 2015, p. 28-29)

Nesse sentido, a música criolla a partir de meados do século XX experimentou um processo de desvinculação de suas origens e passou a ter vínculos com bairros nobres e do litoral limense de classe média e alta - como Miraflores e Barranco, por exemplo. Assim, a música criolla como símbolo passou a representar um ideal de colonização - tinha seu significado ainda arraigado nos seus bairros de periferia, mas representava uma totalidade da cidade de Lima.

Houve, portanto, uma aceitação da música criolla, tanto que foi absorvida nas práticas musicais ditas cultas e nobres como elemento de sua identidade. As populações indígenas, no entanto, permaneciam alheias a essa operação - estavam distantes geograficamente do centro urbano limenho e suas práticas musicais eram permitidas em algumas festividades na forma de alegoria. Nesse contexto, a migração andina foi outro fator que modificou de forma absoluta o panorama sonoro de Lima e suas cenas musicais. (Mendívil, 2015, p. 31). Também foi esse processo de migração interno que possibilitou e levou à emergência de vários tipos de cumbia peruana.

Como argumenta Raúl Renato Romero, a cumbia peruana é resultado de processos transnacionais de intercâmbios culturais - a internacionalização da música caribenha e as migrações internas no país são fatores que se complementam neste processo (Romero, 2007, p. 8). Para o autor, a migração andina que se iniciou nos primeiros anos da década de 1940 foi 
um processo crucial para a consolidação da cumbia. A população migrante provocou um inchaço urbano, forçando com que essas pessoas ocupassem bairros periféricos - formando o que fora chamado de asentamientos humanos. As práticas musicais existentes nesses bairros eram baseadas em músicas andinas, principalmente o huayno. Com o estabelecimento dos migrantes e no espaço de uma geração, o huayno se popularizou de tal forma que surgiu o que Romero chamou de huayno rural - gênero que participou da formação da indústria cultural em Lima a partir da década de 1950. Segundo o autor, o huayno estruturou um mercado popular de música que recebeu a cumbia de maneira rápida e difundiu pela cidade sem dificuldades:

\begin{abstract}
"Mientras que el huayno comercial continuaba congregando multitudes, outro género musical de um país vecino empezó a ganar popularidad a finales de los sesenta: la cumbia de Colombia. La cumbia había evolucionado em esse país de una manera similar al huayno em Peru. [...] No fue sorpresa que em el Perú la cumbia ganara prontamente la aceptación popular. Después de todo, em los cincuenta, la población urbana de Lima había recibido com entusiasmo la rumba cubana, el merengue dominicano u el mamo de Pérez Prado. Lo que distinguía la cuma era que también había sido admitif e las zonas rurales." (Romero, 2007, p. 22-23)
\end{abstract}

A cumbia, importada da Colômbia, foi então recebida por ondas de rádio em diversas regiões do país. Mais do que isso, foi inserida em repertórios dos grupos de música locais e, logo, a cumbia peruana tomou forma. A influência do huayno andino e da migração Andes Lima com certeza foi definitivo para a territorialização da cumbia no Peru a partir de Lima, como explica muito bem Renato Romero em "Andinos e Tropicales". Penso, no entanto, que a importância da região amazônica neste processo deve ser mais explorada.

A importação da cumbia colombiana começou a partir da década de 1950, intensificando-se nos anos da década de 1960. A cumbia peruana, então, começou a tomar forma e consolidar cenas musicais no país em meados dos anos de 1960, mas principalmente na década de 1970 - conhecendo seu auge na década de 1980 (Romero, 2007; Wade 2000). Segundo o historiador Jesus Victor San Roman, os anos de 1943 até 1970 podem ser considerados o período de integração da selva à vida nacional peruana. Este marco inicial é devido à conclusão das obras de uma ferrovia que ligou Pucallpa, cidade portuária importante da região da selva alta, à Lima. Depois dela, outras estradas começaram a ser construídas, com o objetivo de ligar os circuitos fluviais e dos portos amazônicos, com o centro urbano e político do país (Roman, 1994, pp. 201-202). Outra cidade relevante neste processo de integração - de caráter principalmente econômico -, era Iquitos. Capital do maior distrito da região amazônica, Loreto, Iquitos até então era uma cidade de grande importância por ser a principal entrada portuária. A construção da ferrovia Pucallpa-Lima deslocou sua 
centralidade, porém, junto à Pucallpa, formou um dos principais circuitos fluviais do país a partir do rio Ucyalli.

Desde então, a região amazônica do Peru sofreu modificações: processos de industrialização; migração interna da região para cidades como Iquitos e Pucallpa; intensificação do comércio informal e aumento das importações na região. Além disso, a comunicação com outras regiões do Peru se intensificaram a partir dessa malha ferroviária que unia o interior do continente com seus portos fluviais:

\footnotetext{
“A partir de 1943 fecha de comienzo del petróleo la curva de intercambio con la costa, tanto en personas como en productos, aumentó a ritmo acelerado llegando a alcanzar cantidades relativamente importantes. El número de pasajeros en el aeropuerto de Iquitos, llegó durante el año de 1967, a 109,689 (53,235 entradas y 56,454 salidas); y, en el aeropuerto de Pucallpa, a 44.520 (22,410 entradas y 22,110 salidas). Y. sumando las cifras desde 1952 a 1970

arrojan un total de 727,983 (347,480 entradas y 380,593 salidas) para el aeropuerto de Iquitos y de 340.298 (166.996 entradas y 173,302 salidas) para el de Pucallpa21. Esta comunicación se ha realizado en su mayor parte con Lima. Ahora bien, las causas que han motivado estos desplazamientos. han sido múltiples: unas veces, el estudio o el trabajo, otras la salud o asuntos administrativos, y otras la distracción, el descanso, etc.

Esta comunicación de crecimiento acelerado, ha determinado una presencia, cada vez más intensa, de la costa en la selva. Lima se ha hecho presente con la ciencia de sus Universidades, con su ambiente cultural y com muchos modelos de comportamiento." (Roman,1994, p. 219)
}

A década de 1970 inaugura um período onde o intercâmbio, comercial e cultural, já estava se consolidando entre a região da selva amazônica e a capital. É esse também o período em que a música caribenha fora importada por todo o país, principalmente a partir das rádios. Além disso, as indústrias fonográficas e empresas discográficas se consolidavam e surgiam na capital como produtoras e distribuidoras da música peruana. É nesse contexto em que grupos da região amazônica conseguem viajar à Lima e gravar com importantes selos musicais, ganhando espaço na cena musical da capital.

Sendo assim, penso que a sonoridade da região amazônica, principalmente na figura de grupos de cumbia da década de 1970, seja importante para refletir na consolidação da cumbia peruana em Lima neste período. Retomando a proposta de Mendívil de usar como metodologia a definição de cenas musicais, proponho que esta relação tenha se dado a partir da união de duas cenas musicais - a de Lima, marcada pela migração andina, pelo inchaço urbano e pela consolidação da indústria musical a partir das estruturas de grandes concertos de huayno e das rádios e várias empresas de disco; e a da região amazônica, marcada pela influência da música caribenha e das regiões amazônicas do Brasil e da Colômbia, e do 
aumento do caráter cosmopolita e comercial que algumas cidades apresentaram após a integração da selva aos circuitos nacionais de transporte e comércio.

É nesse sentido que considero a atuação da INFOPESA com os grupos de cumbia amazônica interessante. O primeiro LP do grupo Juaneco y Su Combo, de Pucallpa, foi gravado em 1971, na cidade de Lima. Alberto Maraví, no encarte de um CD de Juaneco y Su Combo, relançado recentemente pelo selo, conta um pouco de suas impressões dos primeiros anos de trabalho com o grupo:

“En 1972, conocí y pude escuchar a Juaneco y su tribu musical en una calurosa tarde de sábado en Iquitos y los invité a viajar a Lima. De esta forma, se grabó el primer disco en los estudios de INFOPESA, en donde se indició y perennizo el 'Poder Verde' de la cumbia amazónica.

Luego del impactante debut discográfico de 'Juaneco y su Combo' en 1972, se inició la histórica grabación de "El Gran Cacique", su primer long play. En este LP, se le sugirió a Juaneco que se grabara en castellano la inolvidable toada brasileña "Mulher Rendeira" en la voz de Wilindoro Cacique. Este tema tradicional había sido re-versionado por el cantate folklórico Zé do Norte e incluido, también, en la banda sonora de la película "O Cangaceiro", la cual consiguió el primer puesto en el Festival de Cannes." (Maraví, 2016)

Além de elementos da selva peruana, o grupo Juaneco y $\mathrm{Su}$ Combo, por sua proximidade maior com cidades brasileiras e amazônicas, também comunicavam elementos que enunciam uma amazônia regional. Produziam representações que demonstram que a região amazônica é mais vívida e dinâmica culturalmente do que algumas outras representações mais clássicas da selva poderiam sugerir. Outro grupo importante que fora gravado pela INFOPESA, é o famoso Los Mirlos de Moyobamba. Esta é uma cidade da selva baixa peruana, apresenta mais proximidade com a região serrana do país, ao contrário de Pucallpa, localizada mais ao oriente. Sobre a gravação com o grupo, Alberto Maraví diz:

\footnotetext{
“Antes de finalizar el año de 1973, INFOPESA editó el primer LP de Los Mirlos de Moyobamba titulado EL SONIDO SELVÁTICO DE LOS MIRLOS, difundiendo con gran éxito el novedoso y cadencioso ritmo tropical de la cumbia amazónica. Este sonido era muy diferente al de la cumbia costeña y la cumbia andina y, además, logró impactar el ambiente musical de las fiestas patronales y los espetáculos bailables de Lima y las ciudades de Pucallpa, Tarapoto, Tingo María, Huanuco e Iquitos.

De esta manera; se inició, en Lima y Provincias, la promoción del estilo instrumental y la percusión cadenciosa de la cumbia amazónica de esta agrupación, caracterizada de manera especial por el sonido de las guitarras electrónicas de Gilberto Reátegui y Danny Jhonston, los cuales identificaron al conjunto en su primer LP. Este LP incluía un diversificado repertorio de cumbias y cumbiones como "El sonido de Los Mirlos" "Don Agucho" "Lenita", "Chiquita Bonita", "Bailando con Rosita", "Hermosa Flor" y "Makumba".” (Maraví, 2012)
} 
A cumbia amazônica, portanto, surgiu de uma cena musical específica da região amazônica - e que sugere um intercâmbio musical intenso entre os países que dividem a fronteira amazônica; ainda, foi elemento constitutivo da cena musical de cumbia peruana que se consolidou em Lima a partir da comercialização desse gênero musical. Ou seja, nas cidades amazônicas, o ritmo marcado da cumbia colombiana e o compasso acentuado pelos tambores de origem africana foram muito bem recebidos pelos mais variados ritmos populares da região - inclusive a toada brasileira. Isso já é resultado de uma integração regional significativa (Metz, 2011: 171). A cumbia se forma no país como um gênero musical típico, que carrega símbolos de identidade nacional. A cumbia amazônica, neste contexto, foi um relevante elemento neste processo - criando representações da Amazônica nesta construção simbólica, mas também informando a cena musical de Lima com a musicalidade da região amazônica que engloba também sonoridades do Brasil e da Colômbia.

\section{Conclusões}

O objetivo deste artigo era fundamentar, de forma teórica, a proposta de análise que considera a cumbia amazônica como um gênero musical com potencial de se desterritorializar e, nesse processo, produzir representações sobre a região amazônicas que tensionam a relação entre esta região e o restante do país, principalmente ao ser veiculada e consumida em Lima, a capital. Considerando os contextos de mundialização da cultura que marcam a modernidademundo, a cumbia, desde a Colômbia e sua internacionalização a partir da década de 1940, criou espaços interculturais na região do continente latino-americano que, dentro de suas fronteiras nacionais - a partir da atuação das indústrias discográficas nacionais - tensionaram relações fronteiriças regionais. Defendo que esse processo, no caso da Cumbia Amazônica, deu-se a partir da construção e difusão de representações da Amazônia a partir da música - na imagem de bandas como Los Mirlos e Juaneco y Su Combo, produzidas pela INFOPESA.

Este é um tema que possibilita várias abordagens e questões a serem contempladas. Não possuo escopo teórico e nem tempo hábil para, por exemplo, pensar em como identidades étnicas - de grupos indígenas - são acionadas a partir da estética do grupo Juaneco y $\mathrm{Su}$ Combo. Outro elemento que me chama atenção também é a representação da mulher nas capas de discos e em alguns shows e apresentações desses grupos. São temas que considero relevantes e que se apresentaram de forma contundente no levantamento de dados - capas de discos e análises das letras. Para a minha pesquisa de mestrado, entretanto, o que pretendo abordar é como a cumbia, em especial a amazônica, pode configurar elemento de integração 
cultural para o continente latino-americano - em especial entre os países que compartilham a fronteira amazônica.

\section{Referências}

IANNI, Octávio. As Ciências Sociais na época da globalização. Revista Brasileira de Ciências Sociais. Vol. 13 n. 37, São Paulo, Junho de 1998.

L'HOESTE, Héctor. Vila, Pablo. "Introduction" In:

(Editores). Cumbia!: Scenes of a Migrant Latin American Music Genre. Duke University Press, 2013. p. XX-YY

MENDÍVIL, Julio. "Lima es muchas Limas". Primeiras reflexiones para una cartografia musical de Lima a principios del siglo veintiuno. In: ROMERO, Raúl (Editor). "Musica Popular y sociedad en el Perú contemporâneo". Lima: Pontifica Universidad del Perú, Instituto de Etnomusicologia, 2015. p. 17-47

METZ, Kathryn. Pandillar in the Jungle: Regionalism and Tecno-cumbia in Amazonian Peru. In: . (Editores). Cumbia!: Scenes of a Migrant

Latin American Music Genre. Duke University Press, 2013. p. XX-YY

MONTERO, Paula. Globalização, identidade e diferença. Novos estudos CEBRAP, v. 49, p. 47-64, 1997.

ORTIZ, Renato. Mundialização e Cultura. São Paulo: Editora Brasiliense, 1994. Ortiz, Renato. Um outro território: ensaios sobre a mundialização.

3. ed. Olho d'água, 2005.

Universalismo e diversidade: contradições da modernidade-mundo.

Boitempo Editorial, 2015.

ROMERO, Raúl. Andinos y Tropicales. La cumbia peruana em la ciudad global. Lima: Pontificia Universidad Católica del Perú, Instituto de Etnomusicologia, 2007. . Introducción. Em: . (Editor). "Musica Popular y

sociedad en el Perú contemporâneo". Lima:Pontifica Universidad del Perú, Instituto de Etnomusicologia, 2015. p. 7-12

ROTONDO, Santiago Alfaro. La music andina como mercado de consumo. In: ROMERO, Raúl (Editor). Musica Popular y sociedad en el Perú contemporâneo. Lima:Pontifica Universidad del Perú, Instituto de Etnomusicologia, 2015. p. 130-182.

OCHOA, Ana María. Músicas locales en tiempos de globalización. Grupo Editorial Norma, 2003. 
RELACult - Revista Latino-Americana de Estudos em Cultura e Sociedade

Revista Latinoamericana de Estudios en Cultura y Sociedad | Latin American Journal of Studies in Culture and Society V. 03, ed. especial, dez., 2017, artigo $n^{\circ} 603$ | relacult.claec.org | e-ISSN: 2525-7870

WADE, Peter. Music, Race and Nation. Chicago: The University of Chicago Press, 2000. 